\title{
Trash-to-Gas: Using Waste Products to Minimize Logistical Mass During Long Duration Space Missions
}

\author{
Paul E. Hintze ${ }^{1}$, Anne J. Caraccio ${ }^{2}$, Stephen M. Anthony ${ }^{3}$, Alexandra N. Tsoras ${ }^{4}$, and Monoita Nur ${ }^{5}$ \\ Engineering and Technology Directorate, NASA Kennedy Space Center, FL 32899 \\ Robert Devor $^{6}$ and James G. Captain ${ }^{7}$ \\ QinetiQ North America, Kennedy Space Center, FL 32899
}

\begin{abstract}
Just as waste-to-energy processes utilizing municipal landfill and biomass wastes are finding increased terrestrial uses, the Trash-to-Gas (TtG) project seeks to convert waste generated during spaceflight into high value commodities. These include methane for propulsion and water for life support in addition to a variety of other gasses. TtG is part of the Logistic Reduction and Repurposing (LRR) project under the NASA Advanced Exploration Systems Program. The LRR project will enable a largely mission-independent approach to minimize logistics contributions to total mission architecture mass. LRR includes technologies that reduce the amount of consumables that need to be sent to space, repurpose items sent to space, or convert wastes to commodities. Currently, waste generated on the International Space Station is stored inside a logistic module which is de-orbited into Earth's atmosphere for destruction. The waste consists of food packaging, food, clothing and other items. This paper will discuss current results on incineration as a waste processing method. Incineration is part of a two step process to produce methane from waste: first the waste is converted to carbon oxides; second, the carbon oxides are fed to a Sabatier reactor where they are converted to methane. The quantities of carbon dioxide, carbon monoxide, methane and water were measured under the different thermal degradation conditions. The overall carbon conversion efficiency and water recovery are discussed.
\end{abstract}

\section{Nomenclature}

$\begin{array}{ll}\mathrm{CH}_{4} & =\text { Methane } \\ \mathrm{CO} & =\text { Carbon monoxide } \\ \mathrm{CO} & =\text { Carbon dioxide } \\ F T I R & =\text { Fourier transform infrared spectrometer } \\ \mathrm{GC} / M S & =\text { Gas chromatography-mass spectrometer } \\ \mathrm{H}_{2} & =\text { hydrogen } \\ \mathrm{HFWS} & =\text { High fidelity waste simulant } \\ I S S & =\text { International Space Station } \\ l & =\text { Liter } \\ L R R & =\text { Logistics Reduction and Repurposing } \\ M A G & =\text { Maximum absorbency garment } \\ N A S A & =\text { National Aeronautics and Space Administration }\end{array}$

${ }^{1}$ Chemist, Chemistry Branch, Mail Stop NE-L6, Kennedy Space Center, FL 32899.

${ }^{2}$ Chemical Engineer, Chemistry Branch, Mail Stop NE-L6, Kennedy Space Center, FL 32899.

${ }^{3}$ Chemical Engineer, Fluids Design Branch, Mail Stop NE-F2, Kennedy Space Center, FL 32899.

${ }^{4}$ NASA Intern, University of Kentucky, Lexington, KY 40506.

${ }^{5}$ NASA Intern, University of Rochester, Rochester, NY 14627.

${ }^{6}$ Chemist, Applied Chemistry Laboratory, QinetiQ North America, Kennedy Space Center, FL 32899.

${ }^{7}$ Chemist, Applied Chemistry Laboratory, QinetiQ North America, Kennedy Space Center, FL 32899. 
$\begin{array}{ll}\mathrm{O}_{2} & =\text { Oxygen } \\ s l m & =\text { standard liters per minute } \\ T t G & =\text { Trash to Gas }\end{array}$

\section{Introduction}

THE Trash-to-Gas (TtG) project is part of the Logistics Reduction and Repurporsing (LRR) funded by NASA's Advanced Exploration Systems. The primary goal of LRR is reducing, reusing or recycling logistical mass used in spacecraft. Lowering the total logistical mass reduces launch costs and frees payload space for other items. The $\mathrm{TtG}$ project seeks to convert waste materials generated during space flight into high value commodities such as methane. Currently on the ISS, trash and waste materials are stored on board, then loaded onto a cargo module which eithers burns up on reentry into Earth's atmosphere or is returned to Earth. A crew of four on a one year mission is estimated to produce roughly $2500 \mathrm{~kg}$ of waste trash, metabolic waste and life support system consumables ${ }^{1}$. $\mathrm{TtG}$ represents a paradigm shift, and considers these wastes a resource rather than an inconvenience. The TtG system could be tailored to maximize recovery of water from the waste, or produce other gasses depending on the application. In addition to methane propolusion, gasses produced from the oxidation of waste, such as carbon dioxide and carbon monoxide, can be used for resistojet propulsion ${ }^{2}$. $\mathrm{TtG}$ technologies will process all combustible waste, including human metabolic waste, thereby reducing the volume of waste that needs to be stored, and stabilizing the waste, minimizing the possibility of unwanted microbial activity on a spacecraft .

The $\mathrm{TtG}$ project is currently investigating multiple processes to identify the best way to process waste ${ }^{3}$. The different waste processing technologies are compared based on overall efficiency, waste throughput, and other factors. This paper reports results on incineration as a method for conversion of waste. Incineration is part of a two step process to convert waste to methane. First, the waste material is oxidized to produce carbon oxides (carbon dioxide and carbon monoxide) and water in the incinerator, Eq 1. Incomplete combustion leads to carbon monoxide and small hydrocarbons as additional products of $\mathrm{Eq} 1$. Then, carbon dioxide is sent to a Sabatier reactor to produce methane, Eq 2. Carbon monoxide can be converted to methane in a similar reaction. The water in the incineration step is collected and sent to an electolyzer for the production of hydrogen for the Sabatier step. Overall, the conversion of waste to methane is limited by the amount of hydrogen in the waste. Additional hydrogen must be supplied to convert all carbon to methane. The amount of carbon dioxide converted to methane can be varied to either maximize the amount of water recovered from the waste, or maximize the amount of methane produced, at the expense of water. Recent estimates ${ }^{1}$ on the amount of methane produced from waste generated by a four person crew on a one year mission range from $930-1490 \mathrm{~kg}$ depending on if methane production or water recovery are given higher priority.

$$
\begin{aligned}
\mathrm{C}_{\mathrm{x}} \mathrm{H}_{\mathrm{y}} \mathrm{O}_{\mathrm{z}}+\mathrm{O}_{2} & \rightarrow \mathrm{CO}_{2}+\mathrm{H}_{2} \mathrm{O} \\
\mathrm{CO}_{2}+4 \mathrm{H}_{2} & \rightarrow \mathrm{CH}_{4}+2 \mathrm{H}_{2} \mathrm{O}
\end{aligned}
$$

Previous studies have investigated incineration and gasification for processing of spaceflight waste., ${ }^{4,5}$ These studies demonstrated feasibility of the process and identified critical reaction parameters for different waste materials. The goals of this testing were to maximize the amount of carbon oxides produced and water collected from the incineration reactor, while minimizing the time required to process the waste. This study focuses only on maximizing gas production according to Eq 1 .

\section{Methods}

\section{A. Reactor System}

The experimental system consisted of a reactor, gas filtration components, condenser and analytical instrumentation to determine the composition of the outlet gas stream in real time. The system components are shown in Figure 1.

The reactor used in this study is similar to a downdraft gasifier. A schematic of the reactor is shown in Figure 2 . The reactor consisted of a stainless steel pipe, $8.25 \mathrm{~cm}$ in diameter and $91 \mathrm{~cm}$ in length with a total volume of 4.81 . Platforms where trash and catalysts could be placed were integrated in the reactor. The trash was loaded from the top of the reactor and placed on the top platform. The trash occupied the top $30 \mathrm{~cm}$ of the reactor, or 1.61 . When a catalyst was used, it was placed $35 \mathrm{~cm}$ below the trash. Air was supplied to the reactor in two locations: either from 
the top of the reactor flowing through the waste, or directly below the waste. The gas exited out the bottom of the reactor.

The reactor had two heaters, one placed around the volume holding the waste and the other around the catalyst. Thermocouples were inserted into the reactor through the top and bottom flanges to allow for monitoring and control of the temperature of the trash and the gas as it flowed down the reactor.

Upon exiting the reactor, the gas passed through a cyclone filter, activated carbon filter, condenser and particle filter, as shown in Figure 1. The amount of water collected by the condenser was measured after each run. Then, portions of the outlet stream were directed to either a Fourier Transform Infrared (FTIR) Spectrometer for quantitative determinations of carbon dioxide, carbon monoxide and methane or to a Gas Chromatograph/Mass Spectrometer (GC/MS) for qualitative determinations of oxygen content and other small hydrocarbons.

The total flow rate of air supplied to the reactor, the split of air going to the top and bottom inlet, and the temperature of the reactor were varied to try and maximize carbon oxide production and reduce reaction time. Initial testing showed that flowing only through the top air inlet led to incomplete combustion and increased tar production, while flowing only through the bottom inlet resulted in long reaction times. The test conditions are shown in Table 1. The temperature was varied between 500 and $600{ }^{\circ} \mathrm{C}$. The air flow for conditions A and D consisted of a total air flow of $5 \mathrm{slm}$ split between the top and bottom inlets. Initially, the air flow was $1 \mathrm{slm}$ in the top and $4 \mathrm{slm}$ in the bottom. The flows were changed in $1 \mathrm{slm}$ increments until the top flow was $4 \mathrm{slm}$ and the bottom was $1 \mathrm{slm}$. Changes to the flow were made at approximately equal time increments throughout the run. In some runs, the carbon dioxide evolution would increase right after the flow ratio was changed and then gradually decrease. Condition B had a constant air flow of $4 \mathrm{slm}$ in the bottom inlet while the top inlet was increased from 1 - 4 slm during the run. Conditions $\mathrm{C}$ and $\mathrm{E}$ had contstant air flows of $5 \mathrm{slm}$ in both the top and bottom inlets.

Table 1. Reaction conditions with varying flow rates and temperatures.

\begin{tabular}{cccc}
\hline Conditon & $\begin{array}{c}\text { Top } \\
\text { Inlet Flow } \\
\text { (SLM) }\end{array}$ & $\begin{array}{c}\text { Bottom } \\
\text { Inlet Flow } \\
(\text { SLM) }\end{array}$ & $\begin{array}{c}\text { Temperature } \\
\left({ }^{\circ} \mathrm{C}\right)\end{array}$ \\
\hline A & $1 \rightarrow 4$ & $4 \rightarrow 1$ & 500 \\
B & $1 \rightarrow 4$ & 4 & 500 \\
C & 5 & 5 & 500 \\
D & $1 \rightarrow 4$ & $4 \rightarrow 1$ & 600 \\
E & 5 & 5 & 600 \\
\hline
\end{tabular}

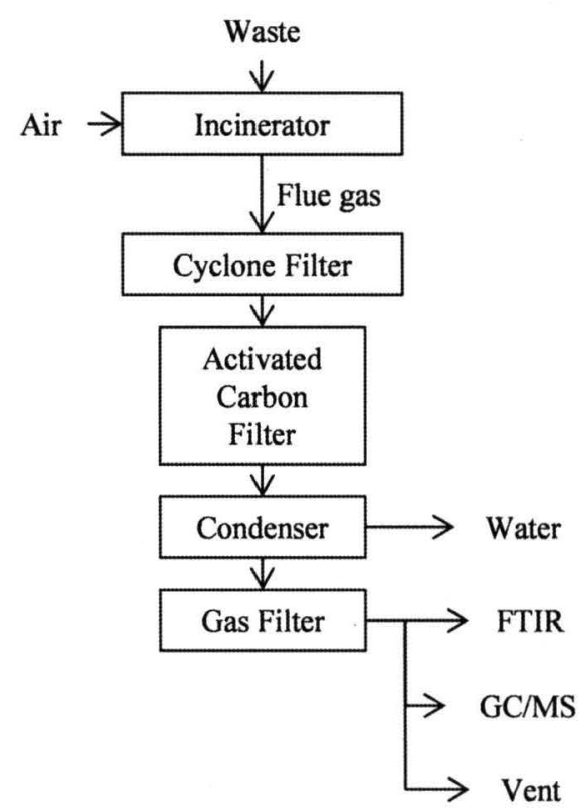

Figure 1. System components.

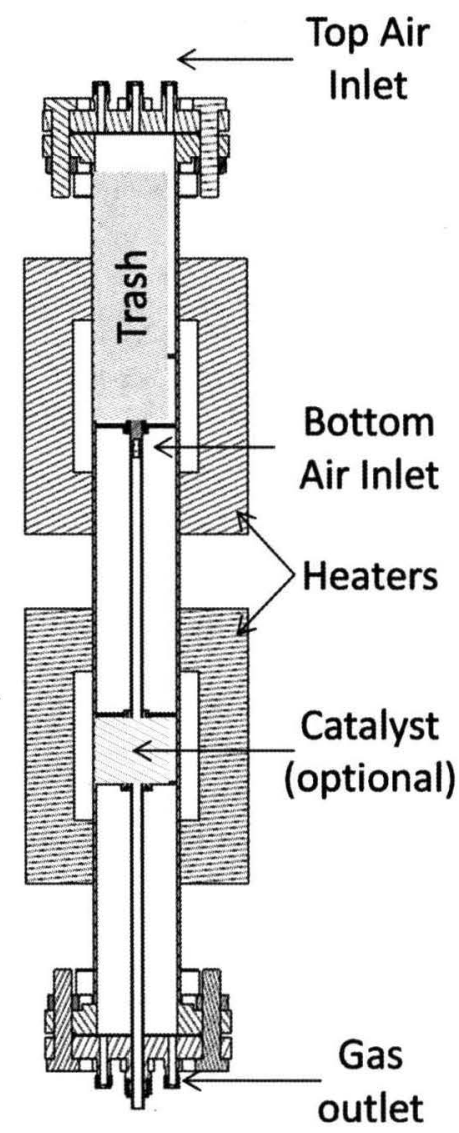

Figure 2. Schematic of incineration reactor. 


\section{B. Waste Simulant}

The major waste sources generated during human space flight include food packaging and left over food, human wastes, hygiene items and clothing. On a dry mass basis, food packaging and clothing are the largest contributors to the waste stream. The waste stream is complex and contains many components including polymers and natural fibers such as cotton and salts. For example, the food packaging is a laminate material that contains polyethylene, nylon, polyethylene terephthalate and aluminum. Because of the complex waste stream, a high fidelity waste simulant (HFWS) was created and used in this testing.

The high fidelity waste simulant (HFWS) is a mixture of materials based on the LRR waste model ${ }^{1}$. It is intended to include all potential wastes including food packaging, food, human wastes, clothing, paper, hygiene supplies and miscellaneous waste. The composition of the waste simulant is given in Table 2 thru 5 . All large items (polyethylene, t-shirts, paper, etc...) were cut into squares about $1 \mathrm{inch}$. The food was prepared by mixing all ingredients in a blender, and blending until homogenous.

Water and ash content of the HFWS were found to be $40.3 \%$ and $5.9 \%$, respectively. Water content was measured by comparing masses of samples before and after heating to $110{ }^{\circ} \mathrm{C}$ for $24-48$ hours. The change in mass divided by the initial mass is the water content. Ash content was measured by heating the dry samples to $575^{\circ} \mathrm{C}$ for six hours. The mass after heating to $575^{\circ} \mathrm{C}$ was divided by the sample mass before drying, to get ash percentage. The ash consisted mostly of aluminum, but also contained salts originiating from the food, urine and fecal simulants.

Table 2. Composition of waste simulant.

\begin{tabular}{cc}
\hline Component & Mass $\%$ \\
\hline Polyethylene sheet $(150 \mu \mathrm{m}$ thick) & $16.20 \%$ \\
Nylon sheet $(113 \mu \mathrm{m}$ thick) & $4.60 \%$ \\
Aluminum foil $(12 \mu \mathrm{m}$ thick) & $2.30 \%$ \\
\hline Urine brine (Table 4$)$ & $21.30 \%$ \\
T-shirts & $12.60 \%$ \\
Fecal Simulant (Table ) & $11.20 \%$ \\
Food (Table ) & $8.90 \%$ \\
Hand/Face Wipes & $5.50 \%$ \\
Tissues (Tech wipes) & $4.90 \%$ \\
Towels & $4.80 \%$ \\
Shampoo & $2.40 \%$ \\
Toothpaste & $1.20 \%$ \\
Nitrile gloves & $2.10 \%$ \\
Paper & $0.60 \%$ \\
MAGs & $0.50 \%$ \\
Disinfecting wipes & $0.40 \%$ \\
Duct Tape & $0.40 \%$ \\
\hline
\end{tabular}

\section{Results}

The amount of carbon dioxide produced, water collected, and reaction times are shown in Figure 3. Carbon dioxide production was dependent on temperature, and had the highest values under reaction conditions $\mathrm{D}$ and $\mathrm{E}$, where the temperature was raised to $600{ }^{\circ} \mathrm{C}$. The flow rate of air did not have an effect on $\mathrm{CO}_{2}$ production, when the temperature was held constant. The reaction time was affected by the air flow rate. The reaction time was fastest under $10 \mathrm{slm}$ air flow, split $5 \mathrm{slm}$ in both the top and bottom
Table 3. Composition of food.

\begin{tabular}{cc}
\hline Food & Mass \% \\
\hline Juice & $41 \%$ \\
Dried apricot & $11 \%$ \\
Tortilla & $21 \%$ \\
\hline Hot dog & $27 \%$ \\
\hline
\end{tabular}

Table 4. Composition of urine brine simulant.

\begin{tabular}{cc}
\hline Urine brine & $\mathrm{g} / \mathrm{l}$ \\
\hline Urea & 70 \\
Sodium chloride & 11.5 \\
Potassium chloride & 12 \\
Calcium sulfate & 1.3 \\
Sodium nitrate & 7 \\
Sodium phosphate monobasic & 5 \\
Potassium sulfate & 30 \\
\hline
\end{tabular}

Table 5. Composition of fecal simulant.

\begin{tabular}{cc}
\hline Fecal Simulant & Mass \% \\
\hline Yeast & $16.5 \%$ \\
Cellulose & $5.5 \%$ \\
Polyethylene glycol & $2.7 \%$ \\
Peanut Oil & $11.0 \%$ \\
Miso & $16.5 \%$ \\
\hline Potassium chloride & $2.2 \%$ \\
Calcium Chloride & $0.5 \%$ \\
\hline Water & $45.1 \%$ \\
\hline
\end{tabular}


inlets, conditions $\mathrm{C}$ and $\mathrm{E}$. The tests that used lower total flows resulted in longer reaction times. The temperature did not have an effect on the reaction time. The ratio of carbon dioxide to carbon monoxide was about 10:1. This ratio did not significantly vary under different reaction conditions. Only trace amounts of methane were produced directly in the incinerator. Condition $\mathrm{E}$ which employed a $10 \mathrm{slm}$ air flow and $600{ }^{\circ} \mathrm{C}$ temperature was selected as the best conditions due to the large amount of carbon dioxide production and fast reaction time.

The carbon conversion efficiency can be calculated by summing the amount carbon produced in carbon dioxide, carbon monoxide, and methane and comparing to the estimated amount of carbon in the HFWS. The conversion efficiency was nearly $100 \%$ when the reactor was heated to $600{ }^{\circ} \mathrm{C}$, regardless of flow rate, and ranged between 50 $85 \%$ at $500{ }^{\circ} \mathrm{C}$. When carbon conversion effiency was low, the remaining carbon was likely converted to tars or volatile hydrocarbons that were not quantified. The mass of material left in the reactor, or ash, was measured after each run. The ash mass was always close to the theoretical value, which is $5.9 \%$ of the original mass of HFWS used in each run, regardless of the carbon conversion efficiency. When the conversion efficiency was low, the carbon was still transported out of the reaction zone in some form other than the desired carbon oxide gasses.

The amount of water recovered did not vary statistically between the different runs. The amount of water recovered was always near the amount of free water in the HFWS, $40.3 \%$ of the original mass or $40 \mathrm{~g}$. There should be more than $40 \mathrm{~g}$ of water produced, since combustion of the waste material produces water in addition to the free water present in the HFWS. This water was not recovered in this system. The lost water either condensed in tubing between the reactor and condenser, or was not collected in the condenser. In future systems, a more efficient condenser will be used. During the most vigorous parts of the reaction, the condenser temperature increased suggesting it was not able to collect all the water.

The incinerator suffered from tar and unwanted hydrocarbon production even when the carbon conversion efficiency was high. The oxygen content exiting the reactor was measured and showed reduction compared to its input concentration ( $21 \%$ of air). However, the oxygen was never completely used in the reaction. The reduction of or combustion of tars will need to be the focus of additional work. Work with the incorporation of catalysts to compelte combustion and reduce tars is ongoing. This system was run at lower temperatures than might be expected for incineration. This was done because of the presence of aluminum in the food packaging. The temperature was kept below aluminum's melting point to prevent it from melting and sticking to reactor walls or fully oxidizing and becoming aluminum oxide ash particles that would need to be cleaned. If the reactor was operated at higher temperatures, tar production may be reduced, but the effect of higher temperature on the aluminum and other ash commponents needs to be monitored.
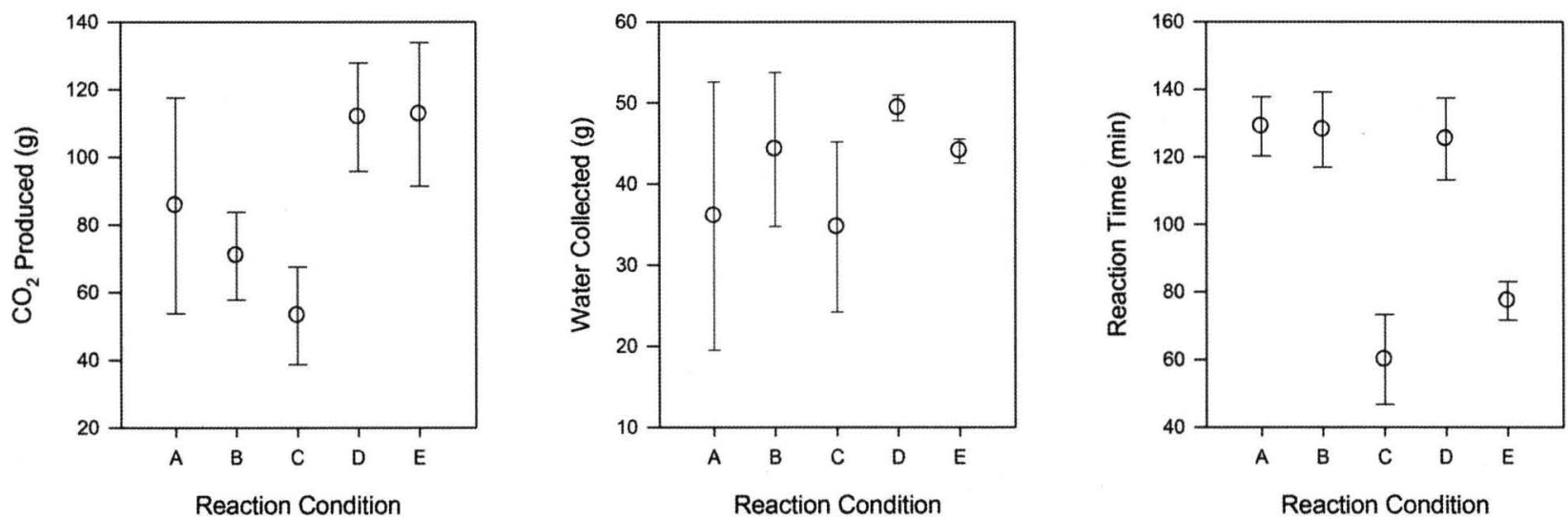

Figure 3. The amount of carbon dioxide produced, water collected, and reaction time for the five reaction conditions given in Table 1.

\section{Conclusion}

Of the reaction parameters evaluated in this study, a $10 \mathrm{slm}$ air flow, split equally between top and bottom inlets and $600{ }^{\circ} \mathrm{C}$ temperature were found to be optimal. This resulted in a near $100 \%$ conversion of carbon in the HFWS into useful carbon containing gasses. It took about 77 minutes to process $100 \mathrm{~g}$ of trash under these conditions. 
This results in a waste processing rate of about $420 \mathrm{~kg} / \mathrm{year}$. This reactor would need to be scaled up by a factor of 5 or 6 to process the $2500 \mathrm{~kg}$ of waste generated by a crew of four. No experiments with HFWS quantities greater than $100 \mathrm{~g}$ have been carried out, leaving uncertainty in the amount of scaling needed. Future work on TtG technologies will focus on the effects of different waste compositions and the minimization of unwanted byproducts.

\section{Acknowledgments}

This work was supported by NASA's Advanced Exploration Systems Program as part of the Logistics Reduction and Repurposing Project. The authors would like to thank all TtG collaborators at NASA's Johnson Space Center, Ames Research Center and Glenn Research Center.

\section{References}

1 Ewert, M.K. and J.L. Broyan, Mission Benefits Analysis of Logistics Reduction Technologies, in 43rd International Conference on Environmental Systems. 2013, American Institute of Aeronautics and Astronautics.

2 MORREN, W., et al., Preliminary performance characterizations of an engineering model multipropellant resistojet for space station application, in 23rd Joint Propulsion Conference. 1987, American Institute of Aeronautics and Astronautics.

3 Hintze, P., et al., Trash to Supply Gas (TtSG) Project Overview, in AIAA SPACE 2012 Conference \& Exposition. 2012, American Institute of Aeronautics and Astronautics.

4 Santiago-Maldonado, E., et al. "Creating Methane from Plastic: Recycling at a Lunar Outpost," 48th AIAA Aerospace Sciences Meeting Including the New Horizons Forum and Aerospace Expostion, AIAA 2010-1551, Orlando, FL, 2010.

5 Caraccio, A.J., et al., Trash-to-Gas: Converting Space Trash into Useful Products, in 43rd International Conference on Environmental Systems. 2013, American Institute of Aeronautics and Astronautics. 